\title{
Spatial and temporal variations of the aftershock sequences of the 1999 İzmit and Düzce earthquakes
}

\author{
Yusuf Bayrak and Serkan Öztürk \\ Karadeniz Technical University, Department of Geophysics, 61080, Trabzon, Turkey
}

(Received February 10, 2003; Revised September 3, 2004; Accepted September 27, 2004)

\begin{abstract}
In this study the properties of the aftershock sequences in the first five months after the 17 August 1999 İzmit and 12 November 1999 Düzce earthquakes are investigated. For this purpose, the $b$-value of frequency-magnitude distribution of earthquakes and temporal decay rate of aftershocks as described by the $p$-value in the modified Omori law are calculated. The data taken from the website of the KOERI consist of 1841 events for the İzmit and 913 events for the Düzce activity, respectively. The $b$-value for the İmit sequence is found as $1.10 \pm 0.03$ with $M c=2.6$ and $b=1.16 \pm 0.05$ for the Düzce sequence with $M c=2.8$. Both $b$-values are close to 1 and typical for aftershock sequences. The $p$-values are calculated as $0.86 \pm 0.05$ for the İzmit and $p=1.34 \pm 0.09$ for Düzce aftershocks, respectively. Small $p$-value found in İzmit sequence may be a result of the background seismicity of the aftershock region. Because of the lower $p$-value for the İzmit activity than that of the Düzce sequence, the aftershocks show a relatively slow decay rate in the İzmit earthquake. Considerable spatial variability is found, $b$-values ranging from 0.8 to 1.6 , and $p$-values ranging from 0.4 to 1.4 . The spatial variations of $b$ and $p$-values of an aftershock sequence may associate with the rupture mechanism and geological structure of an earthquake area. A good agreement between the slip and $b$-value for the Düzce sequence are found whereas we could not observe a linear relation between these parameters for the İzmit sequence. After the İzmit earthquake, the larger $b$-values correlate with the regions where the lower stress changes occurred whereas the lower $b$-values are in the areas with the larger stress variations. Also, the lower and higher $b$-values are related to the higher and lower $P$-wave velocity in general. Regarding the geological aspect, the larger $b$ and $p$-values for the two sequences are related to Holocene alluvium structures which have low velocity. On the other hand, after the both earthquakes, the larger $p$-values correlate well with the regions on which the maximum slip is located and the lower $p$-values are related to the lower slip regions. However, the material properties seem more effective than the stress changes and slip distributions in the $b$-value variations and the slip distribution is the most significant factor on $p$-values in the both sequences.
\end{abstract}

Key words: İzmit earthquake, Düzce earthquake, aftershock, Gutenberg-Richter relation, Omori law.

\section{Introduction}

A number of statistical models have been proposed to describe seismicity characters in time, space, and size of earthquakes. Recent years have shown a significant increase in attention paid to aftershock sequences, because they can provide an understanding of the mechanism of earthquakes and they are potential sources of information about earthquakes nucleation and the physical properties of the materials in fault zone within which slip occurs during an earthquake (Frohlich, 1987). A large amount of residual seismic energy caused by the heterogeneity of materials in focal region is released by the aftershocks. The tectonic setting and the mode of faulting are factors other than the fault surface properties that might control the behavior of the sequences (Kisslinger and Jones, 1991). The characteristics of sequences that may yield useful information are the spatial distribution, total number of aftershocks, and the decay rate of sequence with time. Also, aftershock sequences offer a source of information on the Earth's crust and source prop-

Copy right (c) The Society of Geomagnetism and Earth, Planetary and Space Sciences (SGEPSS); The Seismological Society of Japan; The Volcanological Society of Japan; The Geodetic Society of Japan; The Japanese Society for Planetary Sciences; TERRAPUB. erties of large earthquakes, because a very large number of events occur over a short period of time in a small area.

Two basic relations describe the aftershock activity, the Gutenberg-Richter's (G-R) law which describes the powerlaw of size distribution of earthquakes, and the modified Omori's law which describes the decay rate of the aftershock activity. The size distribution of earthquakes in most cases is well described by the G-R relationship (Gutenberg and Richter, 1944):

$$
\log _{10} N(M)=a-b M
$$

where $N(M)$ is the cumulative number of earthquakes with magnitudes equal to or larger than $M, b$ describes the slope of the size distribution of events, and $a$ is proportional to the productivity of a volume, or the seismicity rate. Although $a$ and $b$-values are determined empirically from seismic catalogues, it is imperative to understand their physical meaning.

The $b$-value is one of the most important parameter in seismology. The $b$-value has been observed to vary spatially as well as temporally. Recently, several studies revealed spatial variations in the frequency-magnitude distribution in various tectonic regimes (Wiemer and Wyss, 1997) by using a technique of high-resolution spatial mapping of the 


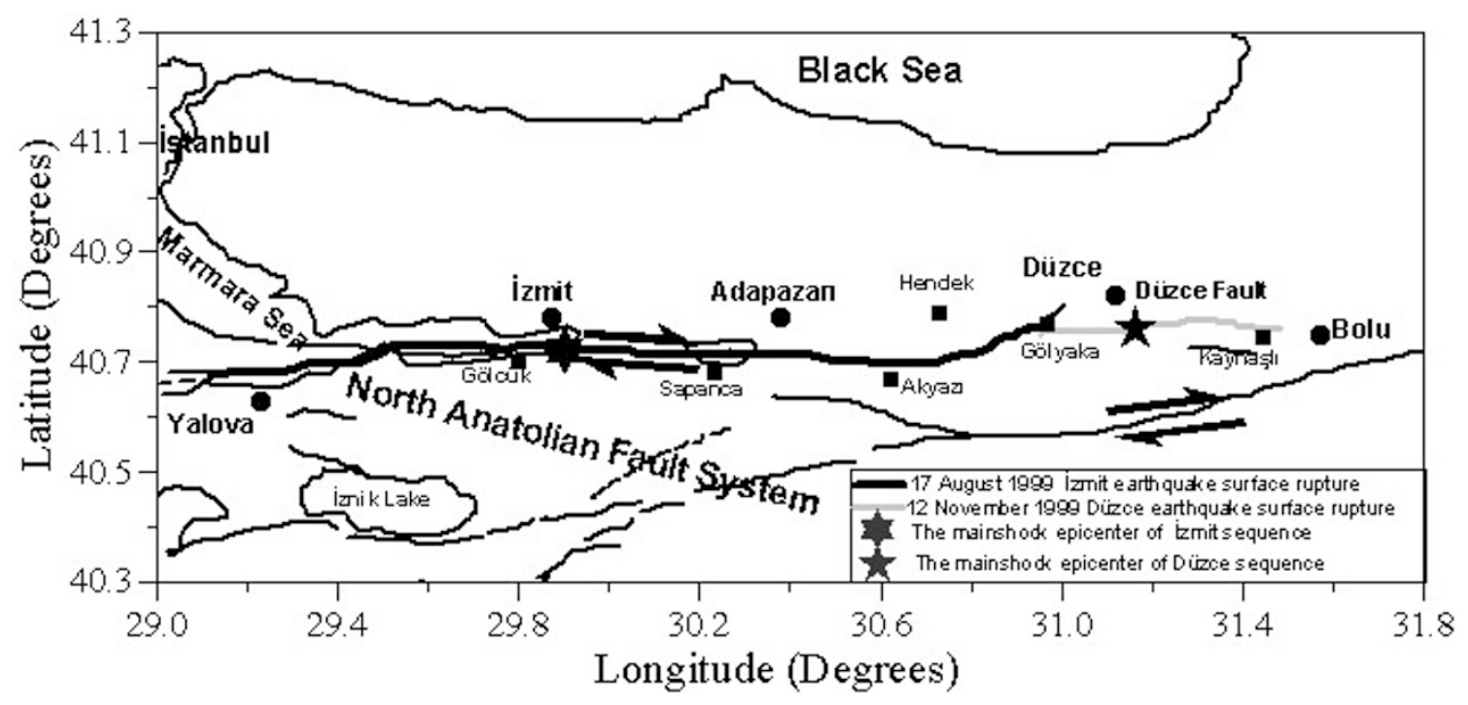

Fig. 1. Mainshock epicenters and surface ruptures of İzmit and Düzce earthquakes taken from Armijo et al. (2002) and main tectonics of surrounding area.

frequency-magnitude distribution. Wiemer and Katsumata (1999) showed that estimated $b$-values vary mostly from 0.6 to 1.4. Also, it is summarized by Utsu (1971) that $b$-values change roughly in the range 0.3 to 2.0 , depending on the different region. Many factors can cause perturbations of the normal $b$-value. The $b$-value for a region does not reflect only the relative proportion of the number of large and small earthquakes in the region, but is also related to the stress condition over the region. The physical implication of the $b$-value, however, is not obvious.

On the other hand, the temporal distribution of aftershocks is empirically well described by the modified Omori law (e.g., Utsu et al., 1995) through the following equation:

$$
n(t)=\frac{K}{(t+c)^{p}}
$$

where $n(t)$ is the number of events per unit time at time $t$ after the mainshock. $K, c$, and $p$ are constants. $K$ depends on the total number of events in the sequence, $c$ on the rate of activity in the earliest part of the sequences. The constant $c$ is a controversial quantity (Utsu et al., 1995) and strongly influenced by incomplete detection of small aftershocks in the early stage of sequence (Kisslinger and Jones, 1991). Of these three parameters, $p$ is a decay parameter and also the most important one, which varies between 0.6-1.8 (Wiemer and Katsumata, 1999), or changes from 0.5 to 1.8 (Olsson, 1999). This variability may be related to the tectonic condition of the region such as structural heterogeneity, stress, and temperature or the crustal heat flow in the source volume (Kisslinger and Jones, 1991; Utsu et al., 1995). However, which factor is most significant in controlling the $p$-value is not clear.

The statistical properties of occurrence of aftershocks have been one of the main objects of seismological studies in connection with the processes of earthquake generation. In this paper, the aftershock sequences of İzmit and Düzce earthquakes causing extensive destruction are considered in order to analyze their spatial and temporal variations.

\section{Aftershock Sequences}

In this study, the aftershock sequences of İzmit and Düzce earthquakes were used to evaluate space-time-magnitude relations. The data used in this study are taken from the website of the Bogazici University, Kandilli Observatory and Earthquake Research Institute (KOERI). The İzmit mainshock $\left(M_{W}=7.4, M_{D}=6.7\right.$, where $M_{W}$ and $M_{D}$ are moment magnitude and duration magnitude, respectively) occurred at $40.75^{\circ} \mathrm{N}$ and $29.86^{\circ} \mathrm{E}$, and at 00:01:37.6 UTC on 17 August 1999 (KOERI). The Düzce mainshock $\left(M_{W}=\right.$ $7.2, M_{D}=6.5$ ) occurred at $40.76^{\circ} \mathrm{N}$ and $31.16^{\circ} \mathrm{E}$, and at 16:57:19.5 UTC on 12 November 1999 (KOERI). These earthquakes were both associated with the North Anatolian Fault (NAF) which is predominantly a single right-lateral strike slip fault (Fig. 1). The Düzce earthquake is related to the Düzce Fault, which is one of the segments of the NAF and extends about $70 \mathrm{~km}$ between the Kaynaşlı and Akyazı. The mainshocks and the observed surface ruptures after the earthquakes are shown in Fig. 1. The rupture plane of İzmit event is about $150 \mathrm{~km}$ and extends about $80 \mathrm{~km}$ east and $75 \mathrm{~km}$ west of the mainshock hypocenter (Özalaybey et al., 2002). The observed surface fault rupture after the Düzce earthquake is about $40 \mathrm{~km}$ (Bürgmann et al., 2002).

Seismological Observatory of KOERI, which has computed the size of aftershock sequences of İzmit and Düzce earthquakes with $\mathrm{M}_{D}$, provides and the real time data with the modern on-line and dial-up seismic stations in Turkey. The seismological division of the KOERI determines, as rapidly and accurately as possible, the location and magnitude of all earthquakes. The KOERI operates a 13station permanent seismic network around the Marmara region (MARNET) in the northwestern part of Turkey. Each station is equipped with a high-gain seismometer. Signals from the stations are sent by phone lines or by radio waves to the seismological center at the KOERI. The aftershocks have been located using both analog and digital records. Averaged uncertainties in the hypocenter locations of the aftershocks are about 2-3 km (Gülen et al., 2002). In this study, we did not relocate the hypocenters of aftershocks and we used the 
(a)

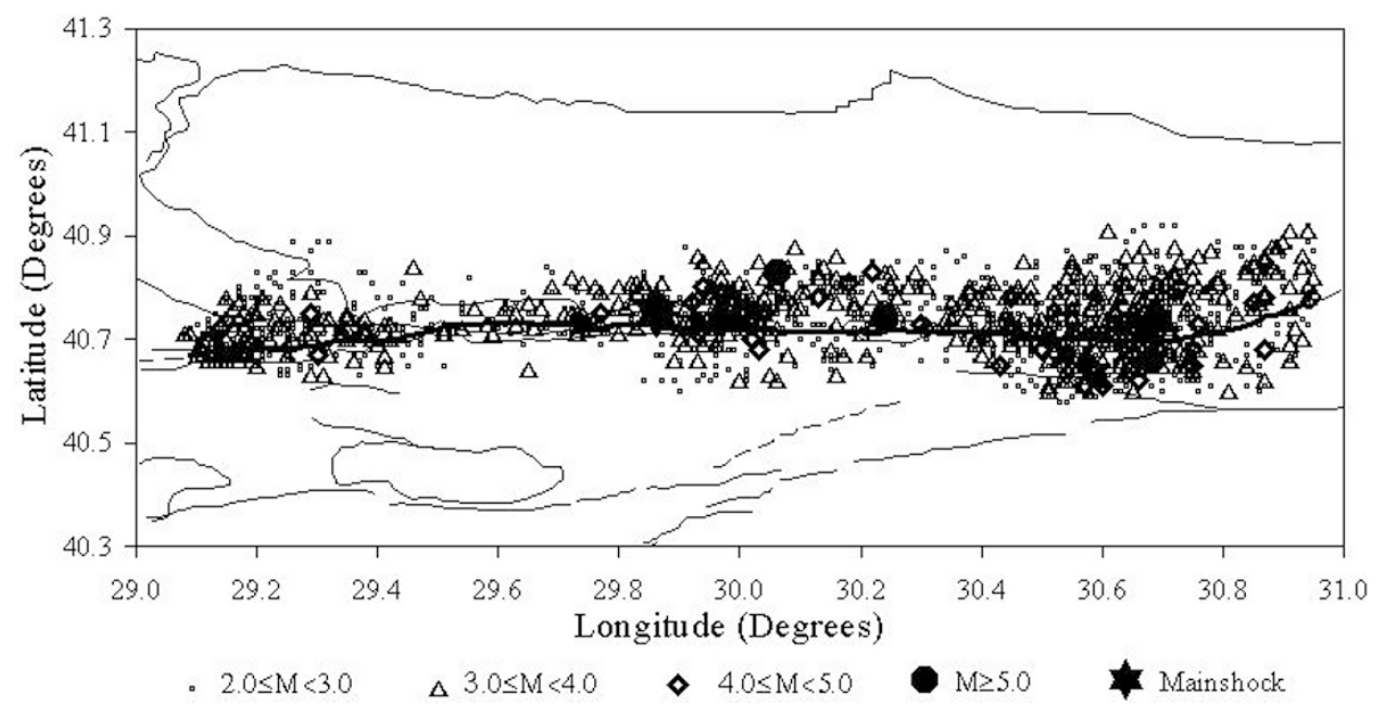

(b)

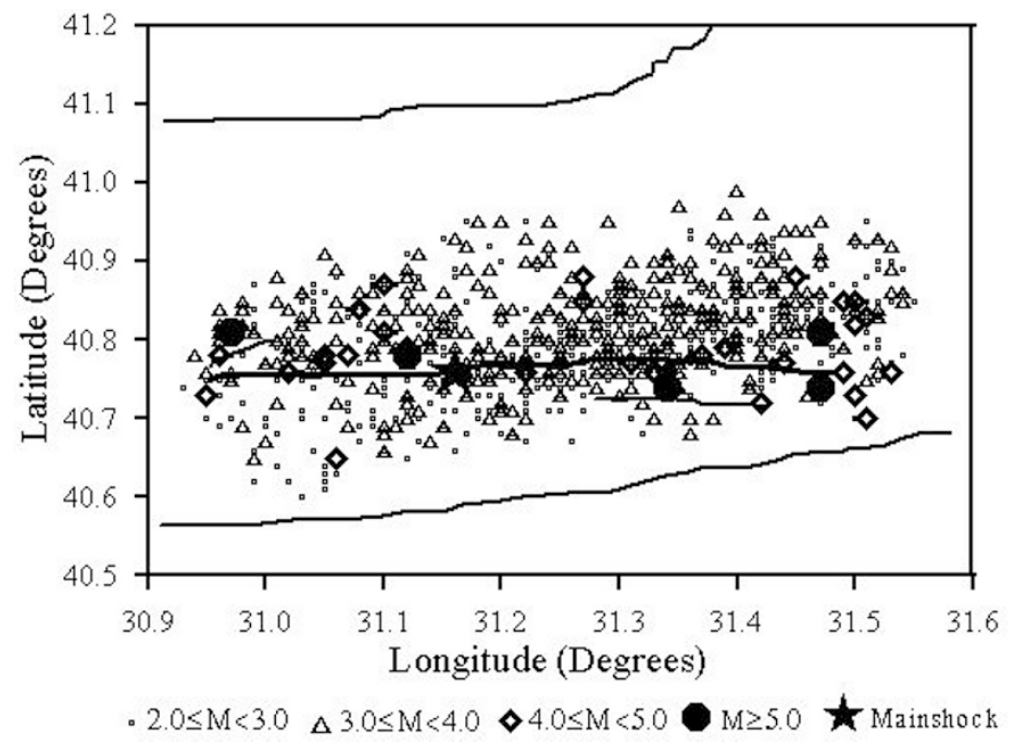

Fig. 2. Epicenter maps for (a) İzmit and (b) Düzce sequences. Data from moderate to large magnitude size of the earthquakes are marked by different symbols and the epicenters of the mainshocks by stars.

hypocenter locations of aftershocks given by KOERI.

The aftershock sequences of the two earthquakes contain about five month's time period, that is, from the time of the mainshock (August 17, 1999) until December 31, 1999 for the İzmit earthquake and from November 12, 1999 until March 31, 2000 for the Düzce earthquake. Figure 2 shows the hypocenters of the aftershock sequences of the two earthquakes. For the İzmit sequence a total of 1841 aftershocks with magnitude $\mathrm{M}_{D}$ larger than and equal to 2.0 were used during the five months time interval. The aftershocks of İzmit are concentrated in three regions. The highest den- sity of events (all size of shocks in general) is observed east part of the mainshock hypocenter, between the Gölcük and Sapanca, in the eastern end (in the vicinity of Akyazı) and western end (around Yalova) of the surface rupture. The larger events $(M \geq 5.0$ are especially observed between the Gölcük and Sapanca and in the environment of Akyazı. Also, there is an activity in the north of Yalova which varies between $2.0 \leq M<5.0$ (Fig. 2(a)). The aftershock data set of the Düzce with magnitude $\mathrm{M}_{D}$ larger than or equal to 2.3 contains 913 aftershocks. More aftershock activity containing generally all size of aftershocks is densely distributed 

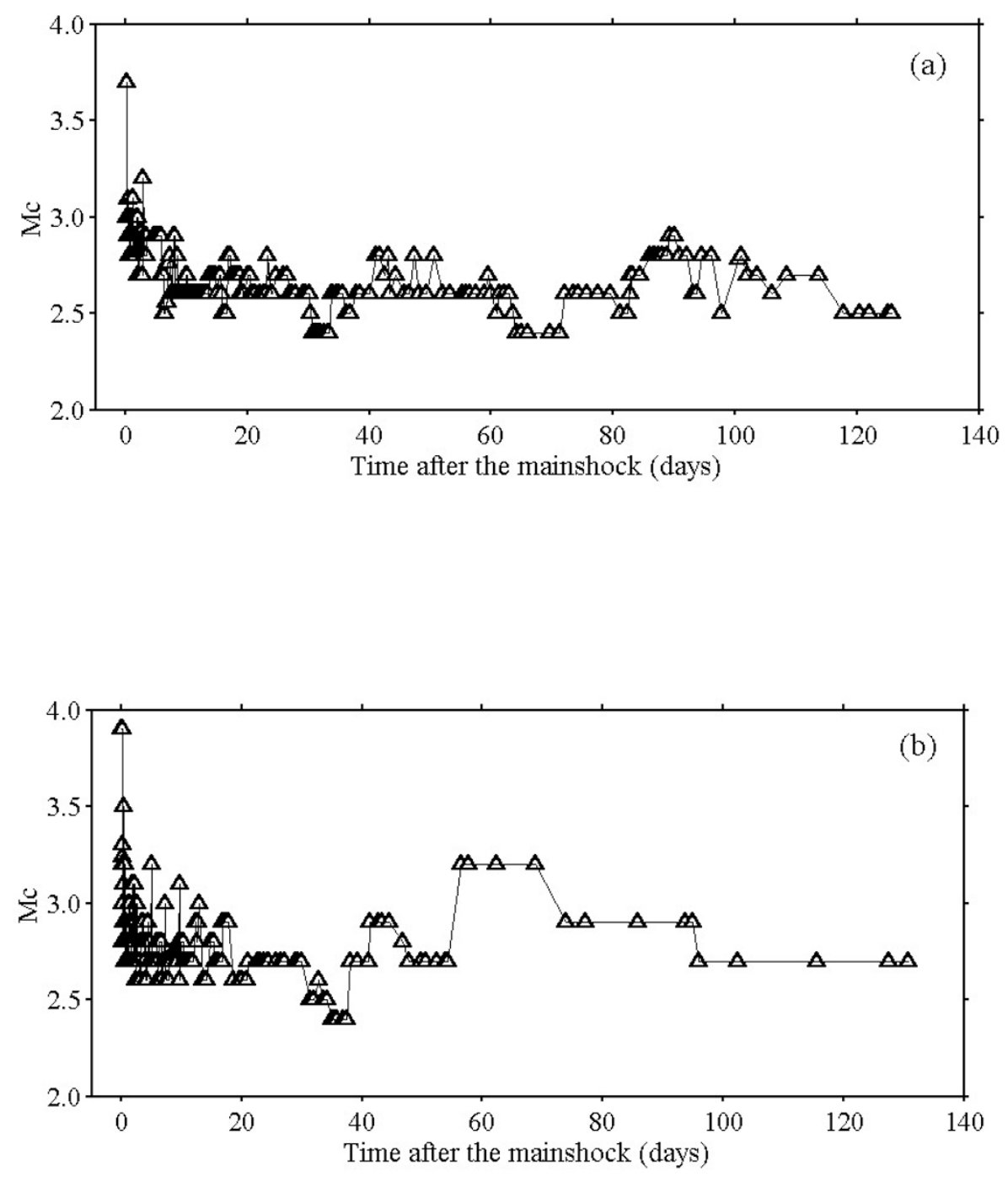

Fig. 3. Magnitude of completeness, $M_{c}$, as a function of time for (a) İzmit and (b) Düzce. $M_{c}$ is computed for overlapping temporal windows, containing 35 events for İzmit and 25 events for Düzce aftershocks.

from the mainshock hypocenter to the NE part of the surface rupture. The larger aftershocks $(M \geq 4.0)$ are abundant in the eastern and western ends of the Düzce Fault (Fig. 2(b)).

\section{Method}

It is important to use a completed data set for all magnitude bands to estimate both the $b$ and $p$-values. The estimate of the magnitude of completeness $\left(M_{c}\right)$ is based on the assumption of G-R's power-law distribution against magnitude. Completeness in magnitude reporting varies systematically as a function of space and time, and particularly the temporal changes can potentially produce erroneous $b$ and $p$ value estimates (Wiemer and Katsumata, 1999). Because the network may be improved after the mainshock and during the first highest activity, small shocks may not be located since they fall within the coda of larger events; $M_{c}$ will be higher in the early part of the aftershock sequence (Wiemer and Katsumata, 1999). The magnitude above which all events have been recorded, $M_{c}$, is important for all seismicity-based studies because it is frequently necessary to use the maximum number of events available for high-quality results (Wiemer and Wyss, 2000). Using a moving window approach (e.g.,
Wiemer et al., 1998) the change of $M_{c}$ as a function of time is determined for two investigated sequences, starting at the origin time of each mainshock. $M_{c}$ is estimated for samples of 40 events/window for the İzmit earthquake and 15 events/window for the Düzce earthquake, respectively. Figure 3 shows the variations of $M_{c}$ with time for both aftershock sequences. $M_{c}$ is highest, 3.9, at the beginning of the sequences (in the first ten hours), and then decreases to about between 2.5 and 3.0 one hour after the mainshock for the İzmit sequence. It also changes from about 4.0 in the first hours to about between 2.4-2.9 for the Düzce sequence after two days from the mainshock (Figs. 3(a) and 3(b)). Therefore, it can be said that $M_{c}$ generally shows a non-stable value in the two sequences. During the five months interval 1841 aftershocks were used for the İzmit and 913 events for Düzce sequences. In order to understand how much the $M_{c}$ variations hinge on the sample size, we tried the different sample sizes such as 35, 45, and 75 events/window for the İzmit and Düzce sequences and saw that the selection of the sample size does not affect the results. Consequently the scatter in completeness seen in Fig. 3 does not depend on the small sample size. 
In order to assure the completeness in our analysis, two parameters need to be adjusted: (1) a minimum magnitude threshold $M_{\min }$ and (2) a minimum time threshold $T_{\text {start }}$ (in days), i.e. excluding the first hours to days from the analysis. $M_{\text {min }}$ would be selected for the shortest $T_{\text {start }}$ as the most simplistic approach and therefore, the approach uses the highest $M_{c}$ identified for the earliest part of the sequence (Wiemer and Katsumata, 1999). This approach, however, reduces the amount of useful data by more than one order of magnitude. For the İzmit sequence $M_{\min }=3.4$ and $T_{\text {start }}=0.01$ and for the Düzce aftershocks $M_{\min }=3.3$ and $T_{\text {start }}=0.01$ were chosen to determine the frequency-magnitude distribution and the parameters of Omori law. Regarding $c$-value (which is measured in time units, days for example) after some earthquakes, usually large ones, there is some delay (usually small) in aftershock occurrence. It can be noticed this by just looking at the decay curve of aftershocks with time. However, in many cases, at the very beginning of the aftershock sequence, there is a large incompleteness of the catalog, so an artificial high $c$-value may be obtained. There is no upper limit of $c$-value. However, this value is usually small or very small: for example around 0.01 . By choosing $M_{\min }=3.4$ and $T_{\text {start }}=0.01$ for the İzmit and $M_{\min }=3.3$ and $T_{\text {start }}=0.01$ for the Düzce sequences we aimed to remove these uncertainties on the estimates. In this way, even though the number of earthquakes is drastically reduced, the earliest part of the sequence is included in the analysis and ensures completeness.

The $b$-value in G-R relationship is calculated by maximum likelihood method, because it yields a more robust estimate than least-square regression method (Aki, 1965). The parameters in the modified Omori formula can be estimated accurately by the maximum likelihood method, assuming that the seismicity follows a non-stationary Poisson process (Ogata, 1983).

We used the software ZMAP (Wiemer and Zuniga, 1994) in all computations. For spatial mapping of the frequencymagnitude distribution and the decay rate of the aftershocks, we used the gridding technique and considered the nearest epicenters, $\mathrm{Ne}$, for each node of the grid (Wiemer and Wyss, 1997; Wiemer and Katsumata, 1999). The algorithm (Wiemer and Wyss, 2000) determines the minimum threshold magnitude for which the goodness of fit is greater than or equal to $95 \%$. If there is no such magnitude for the given confidence level, a 90\% goodness of fit is assigned instead. If, however, the goodness of fit is less than $90 \%$ for any threshold magnitude, the magnitude where the frequencymagnitude distribution has its maximum curvature is determined. One of these magnitudes becomes the $M_{c}$ for that grid point. If the number of earthquakes with $M \geq M_{c}$ is larger than or equal to minimum number of the nearest epicenters, $N e_{\min }, b$ and $p$-values are computed for that node by using only the earthquakes with $M \geq M c$. Otherwise, the $b$ and $p$-values are not computed. The $b$ and $p$-values estimated in each node are translated into a color node.

\section{Statistical Properties of Aftershock Sequences}

Figure 4 shows the plots of cumulative number of the aftershocks against the magnitude for the İzmit and Düzce earthquakes, respectively. The completeness magnitude $M_{c}$ was taken as 2.6 for the İzmit and 2.8 for Düzce sequences. These magnitudes were computed automatically by ZMAP program, ranging within the variation of $M_{c}$ shown in Fig. 3. Using these values of completeness it was determined $b$ value and its standard deviation with maximum likelihood method, as well as the $a$-value of Gutenberg-Richter relation. The $b$-value is calculated as $1.10 \pm 0.03$ for the aftershocks of İzmit and $1.16 \pm 0.05$ for Düzce earthquakes (Figs. 4(a) and 4(b)). The $b$-values obtained for the two cases are very close to 1 . So, both aftershock sequences match the general property of aftershocks such that magnitude-frequency distribution of aftershocks is represented by the Gutenberg-Richter law with a $b$-value typically close to 1 .

The temporal decay rates of aftershocks for the two sequences are shown in Fig. 5. The $p, c$ and $K$ parameters were obtained using the maximum likelihood procedure and the occurrence rate was modeled by the modified Omori formula. $p=0.86 \pm 0.05$, relatively small, was calculated for the İzmit sequence considering $M_{\text {min }}=3.4, T_{\text {start }}=0.01$ and $p=1.34 \pm 0.09$ for the Düzce aftershocks assuming to be $M_{\min }=3.3, T_{\text {start }}=0.01 . c$-values are $0.03 \pm 0.03$ and $0.27 \pm 0.11$ for the İzmit and Düzce earthquakes, respectively.

When we compared the decay of aftershock sequences in the İzmit and Düzce, as shown in Figs. 5(a) and 5(b) there is a significant difference in $p$-values between the two distributions. The activity in the Izmit region continues with a large occurrence rate even after five months from the mainshock. But the relaxation time, which ends in about two months, is rather small for the Düzce earthquake and the higher $p$ value, 1.34 , was found for this case. Since aftershocks activity after the İzmit earthquake shows a relatively slow decay rate in time than that of the Düzce sequence, a lower $p$-value is computed for the İzmit sequence.

The small $p$-values especially for the case of small number of aftershocks suggest that the effect of background seismicity has not completely been removed and small $p$-values have often been reported for superposed sequences. The superposed sequences consist of mostly small sized aftershocks and a portion of these may not be real aftershocks; they may only represent background seismicity (Utsu et al., 1995). In our catalogs, İzmit and Düzce sequences have 1288 and 529 events which vary between $2.0 \leq M<3.0$, respectively. Considering the effects of these aftershocks number, we tested the $p$ and $c$-values for the two aftershock sequences based on the KOERI catalog. For İzmit sequence, with $M_{\min }=3.4$ using the data between $0.01 \leq t \leq 30$ days, we obtained $p=0.90 \pm 0.08$ and $c=0.04 \pm 0.04$ for 1155 events, and $p=0.95 \pm 0.07$ and $c=0.06 \pm 0.05$ for 1451 events between $0.01 \leq t \leq 60$ days, and $p=0.85 \pm 0.05$ and $c=0.02 \pm 0.02$ for 1692 events between $0.01 \leq t \leq 90$ days, and $p=0.86 \pm 0.05$ and $c=0.03 \pm 0.03$ for 1841 events between $0.01 \leq t \leq 134$ days. For Düzce sequence, with $M_{\min }=3.3$ using the data between $0.01 \leq t \leq 30$ days, we obtained $p=1.53 \pm 0.18$ and $c=0.41 \pm 0.19$ for 792 events, and $p=1.41 \pm 0.13$ and $c=0.32 \pm 0.13$ for 872 events between $0.01 \leq t \leq 60$ days, and $p=1.38 \pm 0.11$ and $c=0.30 \pm 0.12$ for 887 events between $0.01 \leq t \leq 90$ days, and $p=1.34 \pm 0.09$ and $c=0.27 \pm 0.11$ for 913 events between $0.01 \leq t \leq 139$ days. Consequently, it can 

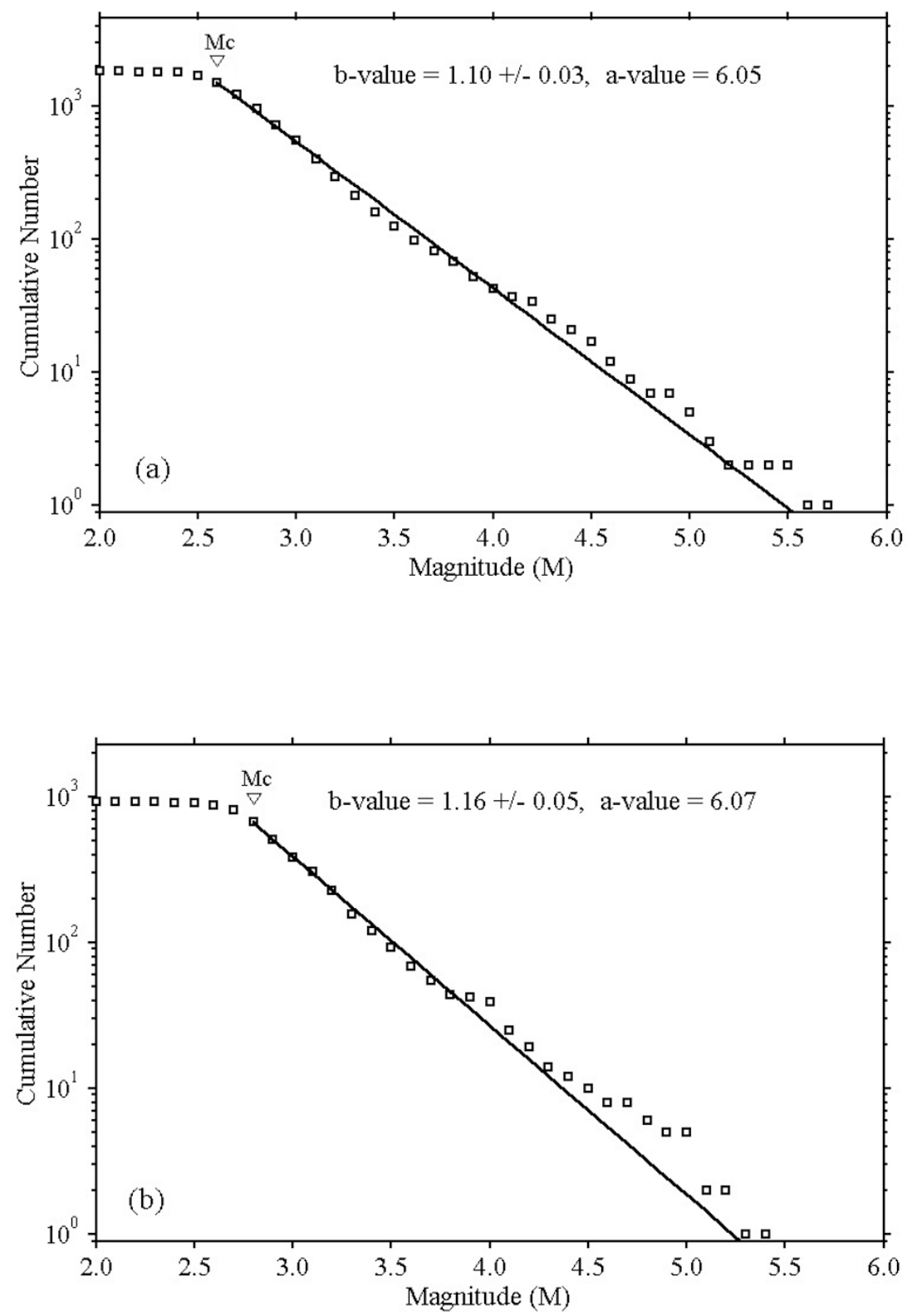

Fig. 4. Frequency-magnitude distributions for (a) İzmit and (b) Düzce aftershocks. The $b$-value and its standard deviation, as well as the $a$-value in the Gutenberg-Richter relation for both sequences are given.

be said that small $p$-value obtained in İzmit sequence in comparison with Düzce events may be caused by the background seismicity of the İzmit aftershock region. Utsu et al. (1995) pointed out that the $p$-value is independent of $M_{\min }$, but the $c$-value depends heavily on the magnitude completeness of the data. We have tested our parameters for other $M_{\min }$ values (ranging from 2.6 to 3.4 for the İzmit and 2.8 to 3.4 for Düzce sequences) and we can conclude that the result does not change significantly.

Some seismologist are of the opinion that the number of aftershocks can not be counted completely in the beginning of a sequence when smaller shocks are often obscured by larger ones due to overlapping, thus too large value of $c$ is obtained. The value of $c$ might be zero if all shocks should be counted (Utsu, 1971). There is an opinion that the $c$-value is essentially 0 and all the reported positive $c$-values result from incompleteness. If $c=0, n(t)$ in Eq. (2) diverges at $t=0$. Kagan and Knopoff (1981) explained this difficulty by considering that the mainshock is a multiple occurrence of numerous sub-events occurring in a very short time interval. Hirata (1969) found $c=0.02-0.5$ for 1969 ShikotanOki earthquake (M6.9; from Utsu, 1969). For simple aftershock sequences following relatively small mainshocks, estimated $c$-values are usually small ( $c \leq 0.01$ days) but if the expansion of the aftershock area occurs in an early stage, a relatively large $c$-value may be obtained (Utsu et al., 1995). Also, the larger $c$-value ( $c>0.01$ days) reflects the more complex feature of the rupture process of the mainshock (Yamakawa, 1968). Although the main rupture of the İzmit earthquake seems more complex than that of the Düzce earthquake, it was found a larger $c$-value for Düzce sequence. Based on the results obtained for both regions, we considered that the larger $c$-value in Düzce sequence may be caused by the large incompleteness at the beginning of 

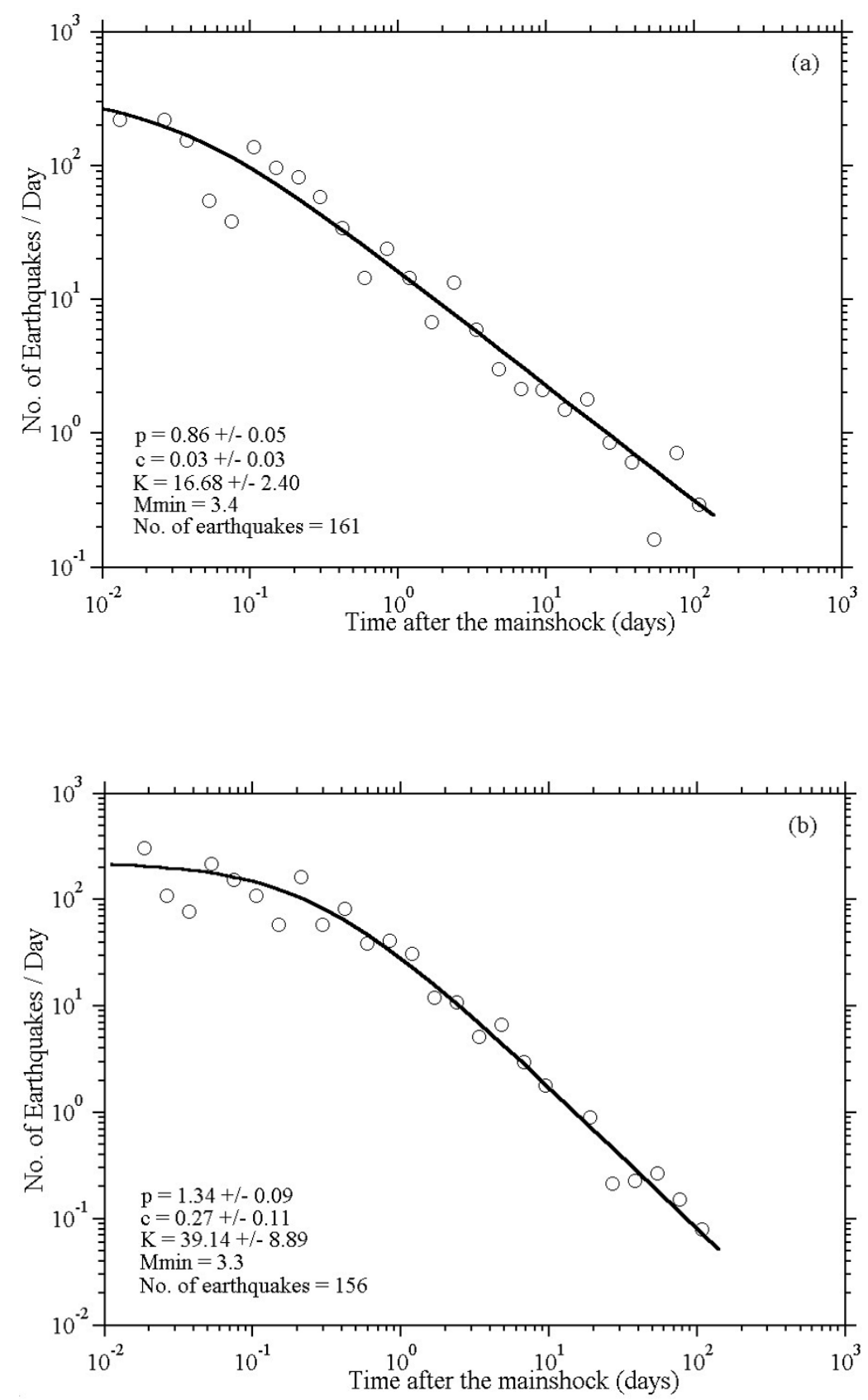

Fig. 5. Temporal change of the number of aftershocks per day (a) İzmit (for the events: $M \geq 3.4$ ), (b) Düzce (for the cases: $M \geq 3.3$ ). Near each distribution some relevant parameters are given: $p, c$ and $K$-values in the modified Omori formula, the minimum magnitude for the data and the number of earthquakes.

the sequence (Fig. 3(b)) and by the fit of the decay rate of aftershocks with time (Fig. 5(b)). In our study, for the two sequences the calculated $c$-values of 0.03 and 0.27 seem to be normal and are consistent with the other studies.

\section{Spatial Variations of $\boldsymbol{b}$ and $\boldsymbol{p}$-values}

Spatial distribution of $b$ and $p$-values for the two aftershock sequences are presented in Figs. 6 and 7, respectively. The İzmit earthquake generated a remarkable set of surface ruptures with a dominant dextral strike-slip character (Polat et al., 2002b). A number of significant aftershock clusters occurred off inferred mainshock rupture plane. The distribution of aftershocks showed a very simple strike slip in the east-west direction along the NAF (Ito et al., 2002). But, the
Yalova cluster which is located to west of $29.2^{\circ} \mathrm{E}$ shows normal faulting mechanisms. Özalaybey et al. (2002) and Ito et al. (2002) inferred that the Yalova cluster was triggered by the mainshock because this cluster activity began after the 19th of August 1999. Ito et al. (2002) concluded that the western end of the rupture of İzmit earthquake was at the longitude of about $29.2^{\circ} \mathrm{E}$ and the eastern end of the rupture at about $31.0^{\circ} \mathrm{E}$. From the aftershock distribution, we concluded that the western end of the rupture is at the longitude of about $29.2^{\circ} \mathrm{E}$ and the eastern end of the surface rupture is about $31.0^{\circ} \mathrm{E}$ for the İzmit sequence. Also, we excluded the Yalova cluster from our analysis. We used the longitudes between $30.95^{\circ} \mathrm{E}$ and $31.55^{\circ} \mathrm{E}$ for the Düzce sequence considering that the part between $30.95^{\circ} \mathrm{E}$ and $31.00^{\circ} \mathrm{E}$ of İzmit 
(a)

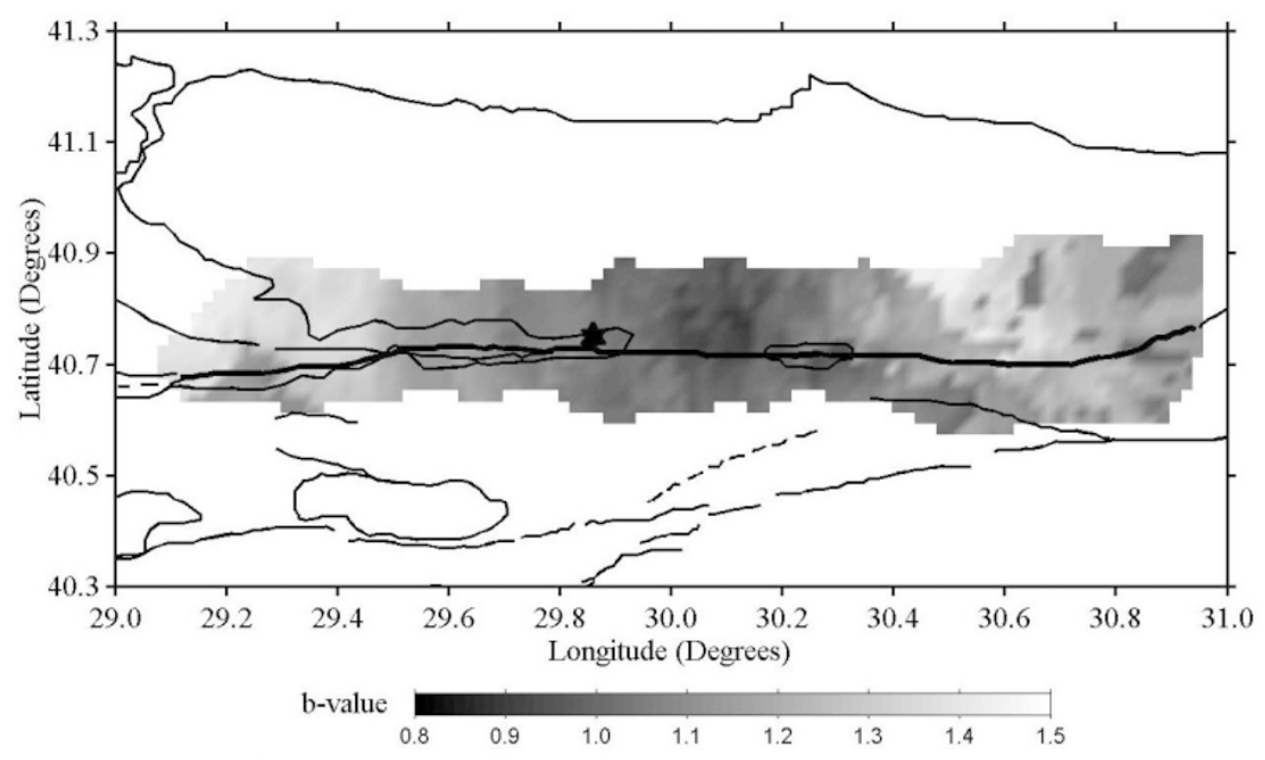

(b)

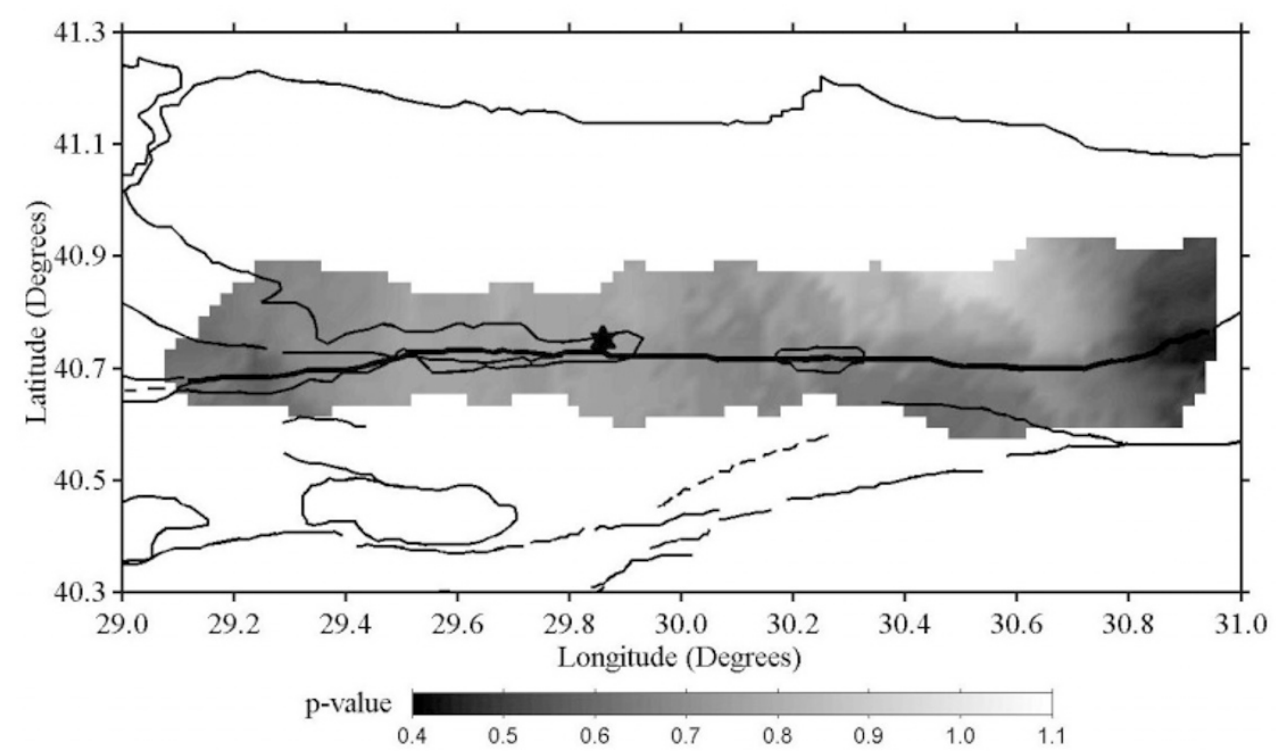

Fig. 6. (a) Map of $b$-value for İzmit sequence using all aftershocks with $M \geq 3.4$ and $T_{\text {start }}=0.01$ days. The $b$-value was computed using the maximum likelihood method and determined by sampling the nearest 250 earthquakes in each node of a grid with nodal separation of $0.02^{\circ}$. (b) $p$-value map using the same grid and number of earthquakes in each grid-node as in the case of $b$-value map. The $p$-value was determined using the maximum likelihood method. The values of $b$ and $p$ are color-coded and plotted at each node.

earthquake reworked (Akyüz et al., 2002).

For the spatial mapping of aftershock sequences, we considered spatial grid of points with a grid of $0.02^{\circ}$ and used the nearest epicenters for each grid points. Next, for each node the closest nearest epicenters (number of events) $\mathrm{Ne}=250$ events for the İzmit and 200 events for Düzce sequence were considered and the minimum nearest epicenters (minimum number of events $>M_{c}$ ) $N e_{\min }$ is taken as 100 for the two sequences. Thus, $b$ and $p$-values for each node are computed by using $N e=250$ and $N e_{\min }=100$ events for the İzmit and $N e=200$ and $N e_{\min }=100$ earthquakes for Düzce. The parameter values for nodes are represented by using a color node on the maps. Two important assumptions are that we chose two fixed $c=0.03$ days for the İzmit and $c=0.27$ days for Düzce events, which is seen in Fig. 5, in the modified Omori formula for the spatial mapping of $p$ value, because these values are more meaningful to produce the contour maps. The magnitude of completeness varies 
spatially between 2.5 and 3.0 , but, for most of the nodes, it has a value of 2.6 for the İzmit events and it has a value of 2.8 for the Düzce sequence. Then, ZMAP selects these minimum threshold magnitudes as the $M_{c}$ for all grid point. If the number of earthquakes with $M \geq M c$ is larger than or equal to $N e_{\min }$ in each window, $b$ and $p$-values are computed for that node by using only the earthquakes with $M \geq M_{c}$. Otherwise, the $b$ and $p$-values are not computed. As a consequence, the $b$ and $p$-values were determined using $N e=250$ events for the İzmit and 200 shocks for Düzce events with $N e_{\min }=100$ events for the two sequences.

Figures 6 (a) and (b) show $b$ and $p$-value maps for the İzmit sequence, respectively. The spatial variations in $b$ change between 0.8 and 1.5 and in $p$ between 0.4 and 1.1 . The highest density and large size of aftershocks of İzmit sequence are observed around the mainshock hypocenter, and especially in the eastern and western extremity of the aftershock region (Fig. 2(a)). The variations of $b$-values along the strike of İmit rupture show considerable spatial variability. The higher $b$-values $(>1.3)$ are located between the Adapazarı and Hendek, in the east of Akyazı and in the western end of the rupture while the lower $b$-values are found in the vicinity of the hypocenter of the mainshock, namely in the central part of the aftershock epicentral distribution (between mainshock hypocenter and the Sapanca Lake). The lower $b$-values $(<1.1)$ are extending both side from the mainshock $\left(29.7^{\circ} \mathrm{E}-30.3^{\circ} \mathrm{E}\right)$. The $p$-values which range from 0.4 to 1.1 show a tendency of decrease and are generally small in the whole investigated area. As shown in Fig. 6(b) the relatively large values of $p(>0.9)$ are observed around the mainshock hypocenter and between the Sapanca Lake and Hendek. Rather low $p$-values $(<0.7)$ are found in easternmost and the western extremity of the surface rupture. The $p$-values in the other parts of the sequence are between 0.7 and 0.8 .

Figures 7(a) and (b) show $b$ and $p$-value maps for the Düzce sequence, respectively. The spatial variations in $b$ change from 0.8 to 1.6 and in $p$ from 1.0 to 1.4 . The $b$-values can be divided into two groups: (1) lower $b$-values $(<1.2)$ to the NW (west of Düzce) and SE (east of Kaynaşlı) direction from the hypocenter of the mainshock, and (2) higher $b$-values ( $>1.2)$ between Düzce and Kaynaşlı. The highest values $(b>1.4)$ are found in the east of the mainshock hypocenter, partially on the surface rupture, and in the northeast part of the sequence. The $p$-values for the Düzce region appear to be normally distributed. The highest $p$-values $(>1.4)$ are found around the hypocenter of the main event and the NE $\left(31.2^{\circ} \mathrm{E}-31.4^{\circ} \mathrm{E}\right)$ of the Düzce rupture area. On the contrary, relatively lower $p$-values $(<1.1)$ areas are computed in the both ends of the main rupture (west of Düzce and east of Kaynaşl1).

\section{Discussion}

The spatial maps of $b$ and $p$-values of an aftershock sequence have provided useful information to interpret rupture mechanisms and materiel properties of an earthquake area. It is known that Eaton et al. (1970) studied firstly the spatial mapping of parameters of frequency-magnitude distribution and $p$ for the Parkfield earthquake sequence. After that, a lot of studies have been done to explain spatial dis- (a)

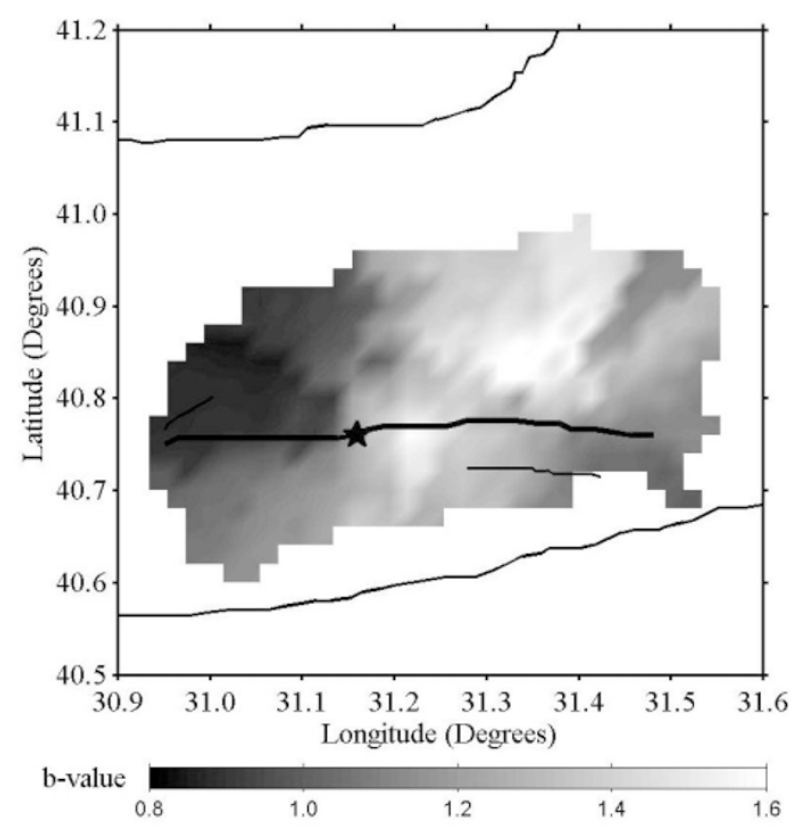

(b)

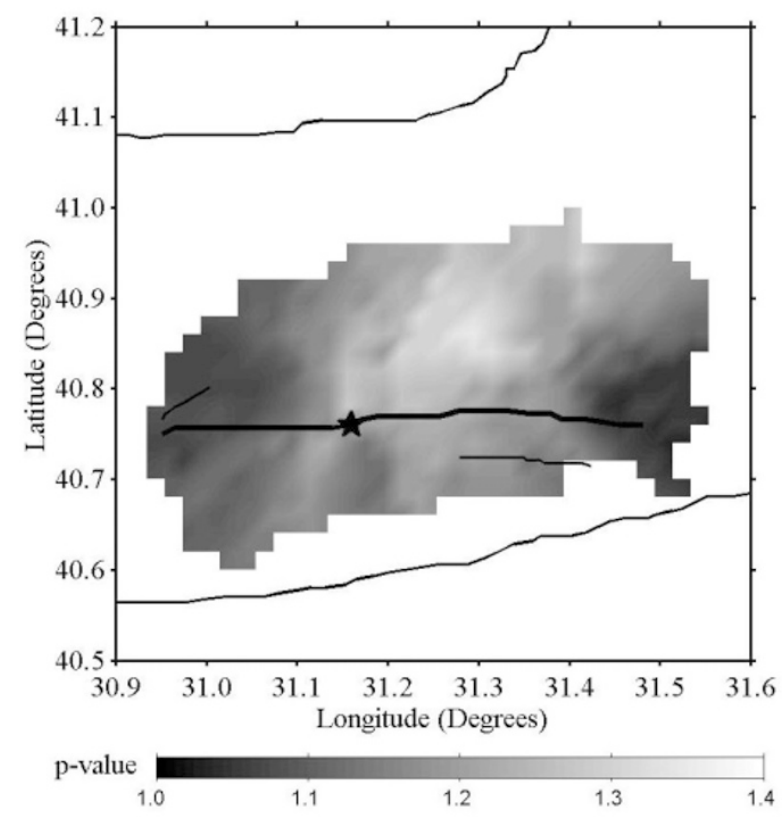

Fig. 7. (a) Map of $b$-value for Düzce sequence using all aftershocks with $M \geq 3.3$ and $T_{\text {start }}=0.01$ days. The $b$-value was computed using the maximum likelihood method and determined by sampling the nearest 200 earthquakes in each node of a grid with nodal separation of $0.02^{\circ}$. (b) $p$-value map using the same grid and number of earthquakes in each grid-node as in the case of $b$-value map. The $p$-value was determined using the maximum likelihood method. The values of $b$ and $p$ are color-coded and plotted at each node.

tribution of the $b$ and $p$-values. In the some of these studies the distribution of $b$-values has been shown to be perturbed by stress and the relation between a lower $b$-value and the higher stress after mainshock is pointed out (Scholz, 1990; 
Frohlich and Davis, 1993; Wiemer and Wyss, 1997; Wiemer et al., 1998; Enescu and Ito, 2002). Kisslinger and Jones (1991) was tested the temporal behavior of 39 aftershock sequences in southern California and could not find any relation of $p$ with either $b$-value of the sequence or the mainshock magnitude. They observed $p$-values varying from 0.688 to 1.809 and suggested a direct correlation between $p$-value and surface heat flow. Wiemer and Wyss (1997) hypothesized that highly stressed asperities might be defined by mapping anomalously low $b$-values for different parts of the San Andreas Fault. Guo and Ogata (1997) was studied 34 aftershock sequences observed in Japan from 1971 to 1995 . They have proposed that the aftershock parameters for intraplate events are mainly affected by heat flow of the area or structural heterogeneity (inverse power distribution of barrier sizes), while those of interplate events are mainly affected by depth. After that, Wiemer and Katsumata (1999) investigated the spatial variability of $p$ and $b$ within one aftershock sequence for Kobe, Morgan Hill, Landers and Northridge earthquakes. Their study is a logical extension of the work by Kisslinger and Jones (1991) and Guo and Ogata (1997). They focused that the areas of largest slip release correlate with high $b$-value, while applied shear stress, crack density and pore pressure govern the frequency-magnitude distribution. Enescu and Ito (2002) analyzed spatial distribution of $b$ and $p$-values of aftershock activity of the 2000 Western Tottori earthquake. They interpreted that the variation of $b$-value can be related to the stress distribution after the mainshock and the larger $p$-values correlate with the regions that experienced larger slip during mainshock.

Yagi and Kikuchi (2000) proposed a source model and slip distribution of the İzmit earthquake by analyzing near-field strong ground motion and teleseismic waveform. The slip distribution in their model was not symmetric and maximum slip values were observed around the mainshock hypocenter and in the east of the Sapanca Lake. Some measurements on the Izmit rupture segments from the Yalova to Gölyaka were made by some researchers (Polat et al., 2002a; Polat et al., 2002b; Barka et al., 2002; Aydın and Kalafat, 2002). They measured the maximum slips are about $5.0 \mathrm{~m}$ between the Karamürsel and Gölcük (west of the mainshock hypocenter), $3.0 \mathrm{~m}$ between İzmit-the Sapanca Lake, $5.0 \mathrm{~m}$ between the Sapanca Lake and Akyazı, and $1.5 \mathrm{~m}$ at the Karadere segment (eastern end of the surface rupture). The slip values decreased to the both ends of the rupture. These studies are consistent with the slip distribution model proposed by Yagi and Kikuchi (2000). In our study, spatial distribution of $b$-value shown in Fig. 6(a) is not consistent with the slip along the rupture zone of İzmit earthquake. Considering the slip values decreasing to the both ends, the lower $b$-values are expected in these regions, namely in the north of Akyazı and in the western end according to Wiemer and Katsumata (1999). But the larger $b$-values are computed in the western end and in the vicinity of Akyazı, so the spatial variation of $b$-value of İzmit sequence is not compared with the slip distribution. As a result, we could not observe a linear correlation between $b$-value and slip for the İzmit sequence and the areas of the largest slip release do not correlate with high $b$-value regions to the contrary of Wiemer and Katsumata (1999). In other words, the smaller and the larger $b$-value regions of the İzmit sequence are generally consistent with the higher and lower slip regions, respectively. However, although no slip occurred in the northeast of Sapanca Lake, the larger $b$-value found in this area may relate to the geological properties. We believe that this conflicted result may be caused by the heterogeneous material properties along the NAF because the rupture is extremely linear but segment and its complexity increase towards the western end manifesting bifurcation (Polat et al., 2002b).

Gülen et al. (2002) reported their observations on the surface fault breaks, distribution of aftershocks, seismicity of the Marmara region, and the results of rupture process analysis, mainly concentrating on the İzmit earthquake. They stated that the stress drop during the mainshock corresponds to $91 \mathrm{Mpa}$ in the east of Lake Sapanca, 11.4 Mpa in the west of Gölcük, 8.4 Mpa between Akyazı and Gölyaka, and 2.7 Mpa in the north of Yalova. Also, King et al. (2001) discussed the implications for seismic hazard of the transient effects of earthquake stress changes and stated that the Coulomb stress resolved onto faults west of the rupture rose by $1-5$ bars and stress was increased by up to 10 bars along the fault at the eastern end of the rupture. Thus, the lower $b$ values in Fig. 6(a) correlate with the regions where the larger stress changes occurred whereas relatively large $b$-value are in the areas with the lower stress variations occurred after the mainshock.

Ogata et al. (1991) found that the variations of the $b$-value estimate is in good agreement with the structure of seismic wave frictional velocity perturbations and stated that the regions of high and low $b$-values correspond, respectively, to the lower and higher parts of the $P$-wave velocity. Also, Young and Maxwell (1992) showed that high seismic velocity characterizes highly stressed regions. Nakamura et al. (2002) determined three-dimensional $P$-wave velocity structure in and around the focal area of 1999 İzmit earthquake. They found two low-velocity anomalies and one high-velocity anomaly in the source region. According their calculations, there is a low-velocity anomaly above the mainshock hypocenter but the mainshock hypocenter is situated in a relatively high-velocity region compared with the surrounding areas. Also, another low-velocity anomaly spreads in a wide area west of the mainshock hypocenter and a highvelocity anomaly to the east of $30.4^{\circ} \mathrm{E}$. This high-velocity area lies below aftershock cluster distributed to the east of $30.4^{\circ}$ E. As shown in Fig. 6(a), the lower and higher $b$-values correlate with the higher and lower $P$-wave velocity in some regions. Comparing these studies, there is low $b$-value region accordance with high-velocity region at the mainshock hypocenter and there is high $b$-value region related to lowvelocity region in the west of the mainshock hypocenter. However, the larger velocity in the northwest of Akyazı and low-velocity computed by Nakamura et al. (2002) does not correspond to the higher $b$-value. Aydın and Kalafat (2002) summarized the result of their field study, which focused on the tectonic significance of the surface ruptures of İzmit and Düzce earthquakes and stated that Holocene alluvium deposits cover the northwest of Akyazı. We found the largest $b$-value in this region as shown in Fig. 6(a) and suggest that the area which has alluvium structure may have low velocity.

On the other hand, the highest $p$-values shown in Fig. 6(b) 
are found around the mainshock hypocenter and in the east of Sapanca Lake where the highest slip observed after the mainshock. Although no slip occurred in the northeast of Sapanca Lake, we found the larger $p$-value in this area and considered that this situation may be caused by the alluvium structure of the region. Also, the calculated lower $p$-values $(<0.7)$ in the eastern and western ends of Izmit rupture are coincide with the observed lower slip values.

Akyüz et al. (2002) stated that an unbroken part of 10$12 \mathrm{~km}$ between the eastern end of the Düzce fault and Bolu may still exist because Düzce was the only segment that had not ruptured in the NAF and the 17 August 1999 İzmit earthquake increased the failure stress on the Düzce segment (Parsons et al., 2000). According to Gülen et al. (2002), the 12 November 1999 Düzce earthquake can be considered as an earthquake-stress triggered, time delayed event following the İzmit earthquake. As shown in Fig. 2(b) aftershocks that vary between 4.0 and 5.5 are concentrated at the both ends of the rupture area and this can be attributed to a stress redistribution process after the mainshock. The lowest $b$ values shown in Fig. 7(a) are calculated in these largest aftershocks areas and it is a reasonable to assume that, during the aftershock sequence in a region of increased Coulomb stress (in the eastern and western end of the Düzce fault), the probability of large event being triggered is greatly increased. Yagi and Kikuchi (1999) calculated slip distribution of the Düzce earthquake using teleseismic body wave ( $P$-waves) data. They suggested the maximum slip $(\sim 5.0 \mathrm{~m})$ was around the mainshock hypocenter. Akyüz et al. (2002) found that the maximum slip which is located on the central part of the surface rupture was about $5.0 \mathrm{~m}$, averaging $3 \mathrm{~m}$. Also, they observed that the slip decreased sharply at both ends of the rupture. The slip distribution of Düzce earthquake which is symmetric with respect to the mainshock hypocenter is not complex as well as that of the Izmit earthquake. Aydın and Kalafat (2002) studied the characteristics of the surface ruptures and associated the slip distributions of İzmit and Düzce earthquakes. They found the highest rightlateral slip (nearly $5 \mathrm{~m}$ ) occurs at the central part and the eastern part of the rupture displays a typical strike-slip deformation with less than about $3 \mathrm{~m}$ right-lateral slip. Also, Bürgmann et al. (2002) stated that distributed-slip inversions indicate maximum strike slip near the center of the Düzce fault close to the earthquake hypocenter. The observed highest slip in the middle of the rupture is consistent with the calculated maximum $b$-values region as seen in Fig. 7(a). Although it is not observed a linear relation between slip and $b$-value for the İzmit sequence, we found a good agreement between the two parameters for the Düzce sequence which is stated in Wiemer and Katsumata (1999). Generally speaking, larger slip must cause larger stress and lower $b$-value. Therefore, the eastern part of the main shock hypocenter is expected to produce the lower $b$-value. As stated in Aydin and Kalafat (2002), the eastern part of Düzce has Holocene alluvium deposits. As in the $b$-value of the İzmit sequence we calculated the largest $b$-value in this region and it can be said that the area which has alluvium structure may produce the larger $b$-values. On the other hand, we calculated the larger $p$-values (Fig. 7(b)) in the central part of the rupture on which the maximum dextral slip is located. Also, the highest $p$-value are observed in the Holocene alluvium region and we interpreted that alluvium structure may correspond to the larger $p$-values. As in the $b$ and $p$-values found in the northeast of Sapanca Lake which has alluvium materials, we observed the higher $b$ and $p$-values in the eastern part of the Düzce sequence, which has alluvium materials. Thus, the larger $b$ and $p$-values may be caused by the alluvium regions. However, the lower $p$-values are calculated in the eastern end western ends of Düzce rupture where the slip decreases. Considering the calculated $p$-values distribution and observed slip values for the both earthquake sequences, we can conclude that there is a linear correlation between $p$-values and slip. This result supports the result found by Enescu and Ito (2002) and Wiemer and Katsumata (1999).

\section{Conclusions}

In this paper the $b$-value of Gutenberg-Richter relation, the $p$-value of Omori's law and the spatial variations of these parameters are investigated for the aftershock sequences of 17 August 1999 İzmit and 12 November 1999 Düzce earthquakes. The results can be summarized as follows:

The $b$-value for the İzmit sequence, computed by using events with $M c=2.6$ equals to $1.10 \pm 0.03$ for the aftershocks of İzmit and $1.16 \pm 0.05$ with $M c=2.8$ for Düzce sequences. There is no significant difference between the two $b$-values. They are very close to 1 and accord with the $\mathrm{G}-\mathrm{R}$ relation with a $b$-value typically near 1 .

The decay parameters of aftershock activity, $p$ in the modified Omori formula are calculated for both cases. Fitting the data for the events with $M \geq 3.4$ of the Izmit sequence, $p$-value was obtained as $0.86 \pm 0.05$, relatively small, and $p=1.34 \pm 0.09$ was calculated assuming to be $M \geq 3.3$ for the Düzce sequence. There is a significant difference in $p$-values between the sequences. The background seismicity of the İzmit aftershock region may cause a small $p$-value in İzmit sequence in comparison with Düzce events. Because of the computed lower $p$-value for the İzmit sequence than that of the Düzce sequence, the activity shows a relatively slow decay rate in the İzmit region.

The spatial variations in $b$-value change between 0.8 and 1.5 and between 0.8 and 1.6 for the Izmit and Düzce sequences, respectively. The highest $b$-values are located between the Adapazarı and Hendek, in the east of Akyazı and in the western end of the rupture while the lowest $b$-values are found between the mainshock hypocenter and the Sapanca Lake. For the Düzce sequence, the lower $b$-values are in the west of Düzce and the east of Kaynaşlı and the higher $b$-values between Düzce and Kaynaşli.

The $p$-values range from 0.4 to 1.1 and from 1.0 to 1.4 for the İzmit and Düzce sequences, respectively. The larger values of $p$ are observed around the İzmit mainshock hypocenter and between the Sapanca Lake and Hendek and the lower $p$-values are found in easternmost and the western extremity of the surface rupture. In the Düzce sequence the highest $p$ values are found around and in the northeast of the hypocenter of the main event whereas relatively lower $p$-values are computed in the east of Düzce and the east of Kaynaşli.

The spatial variations of $b$ and $p$-values of an aftershock sequence may associate with the rupture mechanism and materiel properties of an earthquake area. Although we could 
not observe a linear relation between slip and $b$-value for the İzmit sequence, we found a good agreement between the two parameters for the Düzce sequence. The lower $b$-values correlate with the regions where the larger stress changes occurred whereas relatively large $b$-value is in the areas with the lower stress variations occurred after the İzmit mainshock. The lower and higher $b$-values correlate with the higher and lower $P$-wave velocity in general. On the other hand, for both aftershock activities we calculated the larger $p$-values where the maximum slip is located on and the lower $p$-values are related to the lower slip regions. The larger $b$ and $p$-values are found in the northeast of Sapanca Lake of İmit aftershock region and in the northeast part of the Düzce sequence. From the geological aspect, the larger $b$ and $p$ values for the two sequences are observed in the Holocene alluvium structures which have low velocity. Thus, the larger $b$ and $p$-values obtained in these parts of the sequences may be caused by the alluvium materials.

Our results suggest that the material properties is more important factor in comparison with the stress changes and slip distributions in controlling the $b$-value distributions. But the slip distribution is the most significant factor on $p$-values.

\section{References}

Aki, K., Maximum likelihood estimate of $b$ in the formula $\log N=a-b M$ and its confidence limits, Bull. Earthquake Res. Inst., Tokyo Univ., 43, 237-239, 1965.

Akyüz, H. S., R. Hartleb, A. Barka, E. Altunel, G. Sunal, B. Meyer, and R. Armijo, Surface rupture and slip distribution of the 12 November 1999 Düzce Earthquake (M7.1) North Anatolian Fault, Bolu, Turkey, Bull. Seismol. Soc. Am., 92, 61-66, 2002.

Armijo, R., B. Meyer, S. Navarro, G. King, and A. Barka, Asymmetric slip partitioning in the sea of Marmara pull-apart: A clue to propagation processes of the North Anatolian Fault?, Terra Nova, 14, 80-86, 2002.

Aydın, A. and D. Kalafat, Surface ruptures of the 17 August and 12 November 1999 İzmit and Düzce earthquakes in northwestern Anatolia, Turkey: Their tectonic and kinematics significance and the associated damage, Bull. Seismol. Soc. Am., 92, 95-106, 2002.

Barka, A., H. S. Akyüz, E. Altunel, G. Sunal, Z. Çakır, A. Dikbaş, B. Yerli, R. Armijo, B. Meyer, J. B. de Chabalier, T. Rockwell, J. R. Dolan, R. Hartleb, T. Dawson, S. Christofferson, A. Tucker, T. Fumal, R. Langridge, H. Stenner, W. Lettis, J. Bachhuber, and W. Page, The surface rupture and slip distribution of the 17 August 1999 İzmit earthquake (M7.4), North Anatolian Fault, Bull. Seismol. Soc. Am., 92, 43-60, 2002.

Bürgmann, R., M. E. Ayhan, E. J. Fielding, T. J. Wright, S. McClusky, B Aktuğ, C. Demir, O. Lenk, and A. Türkezer, Deformation during the 12 November 1999 Düzce, Turkey, earthquake, from GPS and InSAR data, Bull. Seismol. Soc. Am., 92, 161-171, 2002.

Eaton, J., M. O'Neil, and J. Murdock, Aftershocks of the 1966 ParkfieldCholame, California, earthquake: A detailed study, Bull. Seismol. Soc. Am., 60, 1151-1197, 1970.

Enescu, B. and K. Ito, Spatial analysis of the frequency-magnitude distribution and decay rate of aftershock activity of the 2000 Western Tottori earthquake, Earth Planets Space, 54, 847-859, 2002.

Frohlich, C., Aftershocks and temporal clustering of deep earthquakes, $J$. Geophys. Res., 92, 13,944-13,956, 1987.

Frohlich, C. and S. Davis, Teleseismic $b$-values: Or, much ado about 1.0,J. Geophys. Res., 98, 631-644, 1993.

Guo, Z. and Y. Ogata, Statistical relation between the parameters of aftershocks in time, space, and magnitude, J. Geophys. Res., 102(B2), 28572873, 1997.

Gülen, L., A. Pınar, D. Kalafat, N. Özel, G. Horasan, M. Yılmazer, and A. M. Işıkara, Surface fault breaks, aftershocks distribution, and rupture process of the 17 August 1999 İzmit, Turkey, earthquake, Bull. Seismol. Soc. Am., 92, 230-244, 2002.

Gutenberg, R. and C. F. Richter, Frequency of earthquakes in California, Bull. Seismol. Soc. Am., 34, 185-188, 1944.

Hirata, T., Aftershock sequence of the earthquake off Shikotan Island on January 29, 1968, Geophys. Bull. Hokkaido Univ., 21, 33-43, 1969 (in Japanese).
Ito, A., B. Üçer, Ş. Barış, A. Nakamura, Y. Honkura, T. Kono, S. Hori, A. Hasegawa, R. Pektaş, and S. M. Işıkara, Aftershock activity of the 1999 İzmit, Turkey, Earthquake Revealed from microearthquake observations, Bull. Seismol. Soc. Am., 92, 418-427, 2002.

Kagan, Y. Y. and L. Knopoff, Stochastic synthesis of earthquake catalogs, $J$. Geophys. Res., 86, 2853-2862, 1981.

King, C. P., G. A. Hubert-Ferrari, S. S. Nalbant, B. Meyer, R. Armijo, and D. Bowman, Coulomb interactions and the 17 august 1999 Izmit, Turkey earthquake, Earth and Planetary Science, 333, 557-569, 2001.

Kisslinger, C. and L. M. Jones, Properties of aftershock sequences in Southern California, J. Geophys. Res., 96(B7), 11,947-11,958, 1991.

Nakamura, A., A. Hasegawa, A. Ito, B. Üçer, Ş. Barış, Y. Honkura, T. Kono, S. Hori, R. Pektaş, T. Komut, C. Çelik, and A. M. Işıkara, P-wave velocity structure of the crust and its relationship to the occurrence of the 1999 İzmit, Turkey, earthquake and aftershocks, Bull. Seismol. Soc. Am., 92, 330-338, 2002.

Ogata, Y., Estimation of parameters in the modified Omori formula for aftershock frequencies by the maximum likelihood procedure, J. Phys. Earth, 31, 115-124, 1983.

Ogata, Y., M. Imoto, and K. Katsura, 3-D spatial variation of $b$-values of magnitude-frequency distribution beneath the Kanto District, Japan, Geophys. J. Int., 104, 138-146, 1991.

Olsson, R., An estimation of the maximum $b$-value in the Gutenberg-Richter relation, Geodynamics, 27, 547-552, 1999.

Özalaybey, S., M. Ergin, M. Aktar, C. Tapırdamaz, F. Biçmen, and A. Yörük, The 1999 İzmit earthquake sequence in Turkey: Seismological and tectonic aspects, Bull. Seismol. Soc. Am., 92, 376-386, 2002.

Parsons, T., S. Toda, R. S. Stein, A. Barka, and J. H. Dieterich, Heightened odds of large earthquakes near İstanbul: An interaction-based probability calculation, Science, 288, 661-665, 2000.

Polat, O., H. Eyidoğan, H. Haessler, A. Cisternas, and H. Philip, Analysis and interpretation of aftershock sequence of the August 17, 1999, İzmit (Turkey) earthquake, Journal of Seismology, 6, 287-306, 2002a.

Polat, O., H. Haessler, H. A. Cisternas, H. Philip, H. Eyidoğan, M. Aktar, M. Frogneux, D. Comte, and C. Gürbüz, The İzmit (Kocaeli) earthquake of 17 August 1999: Previous seismicity, aftershocks, and seismotectonics, Bull. Seismol. Soc. Am., 92, 361-375, 2002 b.

Scholz, C. H., The Mechanics of Earthquakes and Faulting, Cambridge Univ. Press, Cambridge, 439 pp, 1990.

Utsu, T., Aftershocks and earthquake statistics (I): Some parameters which characterize an aftershock sequence and their interrelations, J. Faculty Sci., Hokkaido University, Ser. VII (Geophys.), 3, 129-195, 1969.

Utsu, T., Aftershock and earthquake statistic (III): Analyses of the distribution of earthquakes in magnitude, time and space with special consideration to clustering characteristics of earthquake occurrence (1), J. Faculty Sci., Hokkaido University, Ser. VII (Geophys.), 3, 379-441, 1971.

Utsu, T., Y. Ogata, and R. S. Matsu'ura, The centenary of the Omori formula for decay law of aftershock activity, J. Phys. Earth, 43, 1-33, 1995.

Wiemer, S. and K. Katsumata, Spatial variability of seismicity parameters in aftershock zones, J. Geophys. Res., 104(B6), 13,135-13,151, 1999.

Wiemer, S. and M. Wyss, Mapping the frequency-magnitude distribution in asperities: An improved technique to calculate recurrence times, $J$. Geophys. Res., 102, 15,115-15,128, 1997.

Wiemer, S. and M. Wyss, Minimum magnitude of completeness in earthquake catalogs: Examples from Alaska, the Western United States, and Japan, Bull. Seismol. Soc. Am., 90, 859-869, 2000.

Wiemer, S. and R. F. Zuniga, ZMAP-A software package to analyze seismicity (abstarct), EOS Trans. AGU, 75(43), Fall Meet. Suppl., 456, 1994.

Wiemer, S., S. R. McNutt, and M. Wyss, Temporal and three dimensional spatial analysis of the frequency-magnitude distribution near Long Valley Caldera, California, Geophys. J. Int., 134, 409-421, 1998.

Yagi, Y. and M. Kikuchi, Preliminary results of rupture process for the November 12, 1999 Turkey earthquake, http://wwweic.eri.utokyo.ac.jp/yuji/trk2/Turkeyafter.html, 1999.

Yagi, Y. and M. Kikuchi, Source rupture process of Kocaeli, Turkey, earthquake of August 17, 1999, obtained by joint inversion of near-field data and teleseismic data, Geophys. Res. Lett., 27, 1969-1972, 2000.

Yamakawa, N., Foreshocks, aftershocks, and earthquake swarms (IV)Frequency decrease of aftershocks in its initial and later stages, Pap. Met. Geophys., 19, 109-119, 1968.

Young, R. P. and S. C. Maxwell, Seismic characterization of a highly stressed rock mass using tomographic imaging and induced seismicity, J. Geophys. Res., 97, 12,361-12,373, 1992.

Y. Bayrak (e-mail: bayrak@ktu.edu.tr) and S. Öztürk 